\title{
ROBOMINERS - Developing a bio-inspired modular robot-miner for difficult to access mineral deposits
}

\author{
Luís Lopes $^{1}$, Balazs Bodo ${ }^{1}$, Claudio Rossi ${ }^{2}$, Stephen Henley ${ }^{3}$, Gorazd Žibret ${ }^{4}$, Alicja Kot-Niewiadomska ${ }^{5}$, and \\ Vítor Correia ${ }^{6}$ \\ ${ }^{1}$ La Palma Research Centre for Future Studies SL, Isla de La Palma, Canarias, Spain \\ ${ }^{2}$ CAR UPM-CSIC, Madrid, Spain \\ ${ }^{3}$ Resources Computing International Ltd, Matlock, UK \\ ${ }^{4}$ Geological Survey of Slovenia, Ljubljana, Slovenia \\ ${ }^{5}$ Mineral and Energy Economy Research Institute, Polish Academy of Science, Krakow, Poland \\ ${ }^{6}$ European Federation of Geologists, Brussels, Belgium \\ Correspondence: Luís Lopes (luislopes@lapalmacentre.eu)
}

Received: 16 June 2020 - Revised: 16 June 2020 - Accepted: 9 September 2020 - Published: 20 October 2020

\begin{abstract}
Within the ROBOMINERS project an innovative technology for the future exploitation of small and difficult to access mineral deposits is being studied. The project has two main objectives. First, the development of a bioinspired reconfigurable robotic miner prototype, able to navigate, explore and mine selectively with a certain degree of autonomy. The robot-miner will be able to work under different conditions, making the exploitation of many mineral deposits economically feasible, while reducing social and environmental impacts associated with conventional mining methods. The second objective is the creation of a vision of a new mining ecosystem, its function, parts, research roadmaps and visions for years 2030 and 2050, including creation of novel ideas from other sectors, particularly robotics. The robotic ecosystem concept will be tested in representative sites across Europe with simulations, showcasing the different mining environments and conditions where it can be applied.
\end{abstract}

\section{Introduction}

ROBOMINERS (Bio-Inspired, Modular and Reconfigurable Robot Miners, Grant Agreement No. 820971, http://www. robominers.eu, last access: 7 October 2020) is a European project funded by the European Commission's Horizon 2020 Framework Programme. The project brings roboticists and geoscientists together to create a small robot-miner prototype for mining difficult to access mineral deposits, which can change the current mining paradigm dictated by humans and conventional large machines.

\subsection{Drivers}

ROBOMINERS offers a solution to wider problems related to assuring sustainable supply of mineral raw materials across the European Union, especially addressing the second pillar of the EU (European Union) Raw Materials Initiative, which is securing a supply from domestic sources. The ROBOMINERS concept has been constructed based on a number of drivers:

- EU's dependency on the import of mineral raw materials, especially minerals deemed as critical (European Commission, 2020). This dependency is particularly high for rare metals and elements required for high-tech applications and for the green energy transition outlined in the European Green Deal (European Commission, 2019);

- Need to adhere to the EU's policy on raw materials, supporting the exploration, re-exploration and mining of resources that were economically or technologically unfeasible in the past, or not exploited due to other reasons (European Commission, 2008); 
- Foster innovation for the mining industry through the entire value chain, including down and upstream processes (European Commission, 2008);

- Maintain the EU's forefront position on innovation, especially on the METS (mining equipment, technology and services) and robotics sectors (Forge and Blackman, 2010);

- Possibility of technology transfer to other sectors (e.g. ROBOMINERS application in space exploration or safety).

The ROBOMINERS vision allows for the reopening of abandoned underground mines, without the need for a full recommissioning, and minimising workers exposure to hazards while substantially reducing environmental footprints. As many of them still have valuable amounts of mineral resources feasible to be exploited, it will be possible, thanks to innovative approaches, to resume mining exactly where it was abandoned in the past and turn the mine into a profitable business, with a more socially acceptable and sustainable outlook. Moreover, it could be a modern and revolutionary solution for extraction of small but high-grade and ultra-depth mineral deposits which are currently uneconomic. ROBOMINERS technology eliminates the need for developing typical mining infrastructures on the surface, which represent significant positive environmental impacts and cost effectiveness of mining investment.

\subsection{Objectives and impacts}

ROBOMINERS has set several goals and targets that will justify the success of the project and the approach:

- Construction of a fully functional, modular, robot-miner prototype based on a bio-inspired design. The robot will be capable of operating, navigating and performing selective mining in different mining environments;

- Design of a new mining system, based on future expected upstream/downstream raw materials processes via simulations, modelling and virtual prototyping;

- Validation and showcasing of all key functions of the robot-miner to a TRL (Technology Readiness Level)-4, with the possibility of some components reaching TRL5 , validated in lab and a relevant environment, respectively;

- Use of the robot-miner prototype to study and advance future research on scalability, resilience, reconfigurability, swarm behaviour, selective mining, production tools and methods, among others.

Linked to these objectives, ROBOMINERS envisages positive impacts in the economy, further research and development in raw materials, social and environmental areas. More specifically, the following impacts can be identified:
- Create new exploration scenarios for Europe's domestic mineral resources based on exploitation of any remaining reserves despite the size and geometry of the deposit. The reduction in size of excavations, such as galleries and shafts, brings economic viability which in turn allows exploitation of small deposits under certain conditions;

- Direct and indirect positive economic impact in many regions where the potential for developing mining activities exist, fostering competitiveness within the EU minerals industry and its supplying regions;

- Addressing many of the environmental and social (among others regarding social licence to operate) concerns that are associated with conventional mining, curbing public opposition;

- Creating potential for research, innovation, new technology and business development, not just in mining, but also in other applications where resilient modular robotics could be important, such as disaster relief or space research.

In comparison with conventional mining methods and tools, the ROBOMINERS vision shows the following, specific solutions: (1) No personnel in the mine; (2) Less mining waste; (3) Reduction of mining infrastructure, groundworks and access routes; (4) Cheaper capital cost and quicker set up; (5) Lower costs for addressing and re-addressing mine rehabilitation problems; (6) Development of wellknown but currently uneconomic resources. Furthermore, with ROBOMINERS, underground small-sized mines, will be practically "invisible". This has the potential to greatly reduce the environmental impacts of mining and to enhance the social acceptance of the industry. All these impacts contribute to increasing the well-being of communities at many levels - local, regional, national and even transnational

\section{A new mining concept and reality}

Conventional mining is still based on humans operating in the mine environments and operation centres, with only limited uptake of robotics in the process of exploration, exploitation and processing. Mining occurs either at the surface or underground, and, in some cases, in very challenging conditions (e.g. high temperature, deep, remote locations, extraction below water-bearing horizon, and in physically unstable or toxic geological environments). Moreover, in Europe, there are significant obstacles against mining as it is thought to cause intolerable surface disturbances. Koivurova et al. (2015) suggest six main public concerns and demands' areas towards mining projects (necessary to obtain the Social License to Operate), including: land use, environmental and socio-economic aspects, greater share of benefits from mining activities, more participation in decision making and 
credible assurances regarding safe and responsible operations regarding both working conditions and environmental impacts. The ROBOMINERS new concept, at least in its early and initial stages of development, can answer to three out of six of the aforementioned concerns and challenges:

- Land use: Whole mining infrastructure is reduced so it takes less physical space which in turn means limited land use and competition with other activities. The largest benefit in this regard is, that ROBOMINERS mining methodology relies on smaller autonomous machines, which are able to conduct precise (selective) mining, and thus much less waste is generated. In conventional mining techniques mine spoils, overburden and tailing deposits can occupy significantly larger areas, as mining sites themselves, but we expect large reduction in the need of such waste deposit areas. The possibility to address mine closure easily also contributes to smaller pressure for land uses.

- Environmental aspects: Mining activities in ROBOMINERS entail less waste produced (mineral seams targeted + waste backfills the mined areas), less environmental impacts (decreased visual, sound and dust pollution due to less infrastructure), smaller carbon footprint, low risk of groundwater contamination (less chemicals used), low risk for induced seismicity (site will be pre-assessed), no dewatering needs and associated environmental impacts.

- Socio-economic aspects: address the effect of ageing workforce (there is a shortage of engineers and scientists to take over the work of older professionals), direct and indirect income and employment (new jobs, e.g. truck drivers plus new economic upstream and downstream activities in the value chain), training and skills development to population (in areas including robotics, machine operation) and community development (derived from the previous points).

The application of the ROBOMINERS approach to mining, encompasses the need to create a new mining environment for its application scenarios. In such scenarios conventional mining is usually uneconomical, technologically unfeasible or too dangerous for workers, which are the main factors that lead to mine closure. Furthermore, conventional mining operations require not only considerable capital expenditure, but also come with big earthworks with associated negative environmental impacts. Deriving from these bottlenecks, Social License to Operate, deemed necessary for a mine to operate, becomes difficult to obtain. An innovative solution like ROBOMINERS could be the solution for these problems, unlocking the mining potential in many areas.

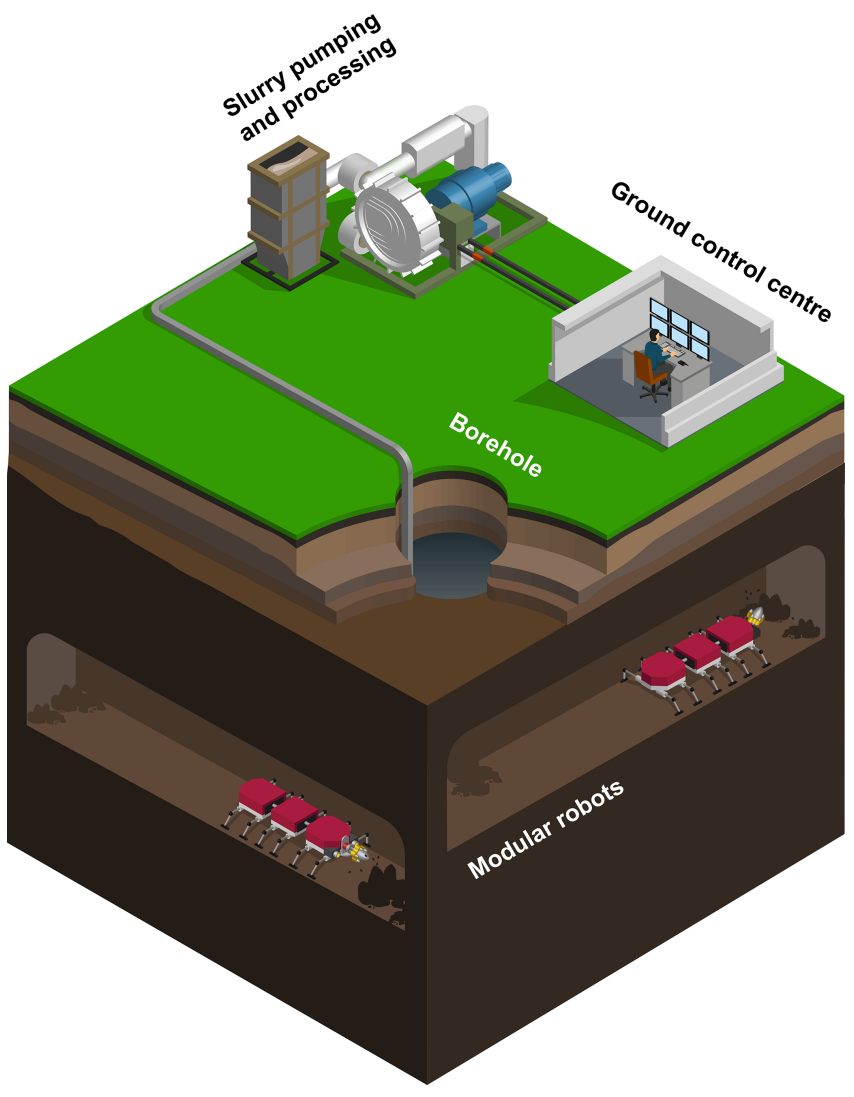

Figure 1. Representative figure of the ROBOMINERS concept showing the main elements.

\subsection{ROBOMINERS mining concept and outline}

In its concept, ROBOMINERS proposes that mining can take place in different conditions. To access the mine, a borehole needs to be drilled from the surface, large enough for the components to pass through. The different modules are then self-assembled underground to make the robot large enough to be able to mine; the robot will have high power density. Awareness and sensing are provided by novel body sensors that merge data in real-time with production sensors, optimising the rate of production and selection between different production methods. Depending on the production rate, the generated high-grade mineral slurry is pre-processed, and pumped to the surface or to a pre-concentrator robot underground. The waste material could then be returned to the mine where it will backfill mined-out areas.

\subsection{ROBOMINERS mining system}

ROBOMINERS concept of exploitation calls for a new approach to mining strategy and mine design: the current extraction system needs to be rethought. The commonly known definition of "mine" (understood as a plant with expanded aboveground and/or underground infrastructure) is changing. The specificities of the concept envisage a new environment, 
where mines are designed as an artificial "ecosystem" with no human life support nor development of extensive underground infrastructure. This adds to health, safety and environmental benefits: tunnels and shafts are minimised in numbers, length and area/volume. The production of waste rock is also minimised due to selective mining and back-filling. With pre-processing of the minerals in the slurry, much of the transport and processing infrastructure is also reduced.

ROBOMINERS mining ecosystem also entails an integrated sustainability assessment. The aim of this assessment is to create a sustainability model that considers environmental, economic, social, policy and ethical aspects of the proposed solution. The novel mining concepts require also re-definition of criteria for economic feasibility assessment of such type of future investments. This will be carried out using any form of discounted cash flow methods (such as Net Present Value, Cost and Benefit Analysis). The base parameters that these models will take into account include financial parameters, the output of the whole system (production rate), expected revenues, investment costs, and operating and maintenance costs. The outcome of this analysis will be an economic feasibility and investment model tailored for ROBOMINERS.

The ROBOMINERS technology, with its novel nature, requires a new approach in the areas of Environmental Impact Assessment and social involvement (often referred to as Social Licence to Operate). It is therefore, mandatory to review key EU and national level regulations and policies, coupled with suggestions/recommendations for new policy measures in respect to regulatory changes concerning the expected initial small scale mining operations based on ROBOMINERS. Integrated analysis to enable the evaluation of the European macroeconomic potential of the ROBOMINERS technology compared to solutions offered by conventional mining will be carried out. The European supply of raw materials will be integrated in the assessment in order to allow the determination of present gross value of potentially extracted materials and the possible future effect of ROBOMINERS operation on supply and demand and the price of critical materials. These steps will build a strong business case.

\subsection{The robot-miner}

The robot-miner concept is developed based on the application environments' specificities. The structure, tools and methods used by the robot are designed to work underground, to allow manoeuvrability in all three directions, with different cutting and auxiliary tools, and with sensors and artificial intelligence to allow autonomy to a certain degree. The miner is currently envisaged to have around $1 \mathrm{t}$ of body weight, with $20-30 \mathrm{~kW}$ of power capacity, running on hydraulic power and will work attached to an umbilical (until the concept is proven). The size of the robot was optimised to allow precision mining, so that it will occupy a completely different niche to conventional mining machines.
From the mining perspective, the miner can be considered small and light, but from the robotics perspective it can be considered as a bigger and much heavier robot (Fig. 2). This brings challenges of adaptation in mixing the two distinct ideas. The robot-miner vision can however change with the study of different possibilities and integration of different concepts. The design and construction is based on seven principles/guidelines that, when put together, can deliver the operating mining machine for the proposed new mining vision:

\subsubsection{Biological inspiration for the robot design}

Bio-inspired robotics gained more and more focus from the research community recently. Examples include MANTIS (https://robotik.dfki-bremen.de/en/research/ robot-systems/mantis.html, last access: 30 August 2020), SILO6 (http://www.car.upm-csic.es/fsr/provisional/silo6/ SILO6_Project.htm, last access: 30 August 2020), or the famous SPOT (https://www.bostondynamics.com/spot, last access: 30 August 2020), robots that take inspiration from real animals for their design and functions. Bio-inspired robots use novel technologies developed through the transfer of functions from biological systems, in an area gaining momentum (Lepora et al., 2013). The fact that these innovative robot designs show effectiveness in locomotion, energy efficiency, resilience, perception and cognition tasks comparing to traditional approaches in robot designs make biological inspiration a guideline for ROBOMINERS. Of interest are burrowing insects which will be used as inspiration (Fig. 3). Some robots, based on burrowing animals have already been developed and tested in laboratory scale with some degree of bioinspiration (Russel, 2011; Zagal et al., 2012). The aim in ROBOMINERS is to mimic their underground locomotion and digging capabilities and their ability to move around in dense mud. Some good case-studies include the centipede (has homogeneous "modular" configuration and is adapted to underground sensing, movement and navigation), the mole cricket (is capable of locomotion in various underground environments) and termites (capable of navigation in complicated underwater labyrinths and use mandibles to digest wood).

\subsubsection{Underground perception and localisation}

Simple but robust perception and localization in underground spaces is required for the robot-miner to operate, as GPS (Global Positioning System) does not work and traditional sensors (e.g. sonar, lidar) are not sufficient for accurate location underground. To solve this bottleneck, the project will study tactile sensing (seen in some animals), conductivity and flow sensing, and sensing relying on inertial movement, temperature, pressure and other parameters, as well as SLAM (Simultaneous Localisation And Mapping) intelligent software solutions using some or all of the sensor data. The goal is to use advanced probabilistic sensor fusion techniques in 


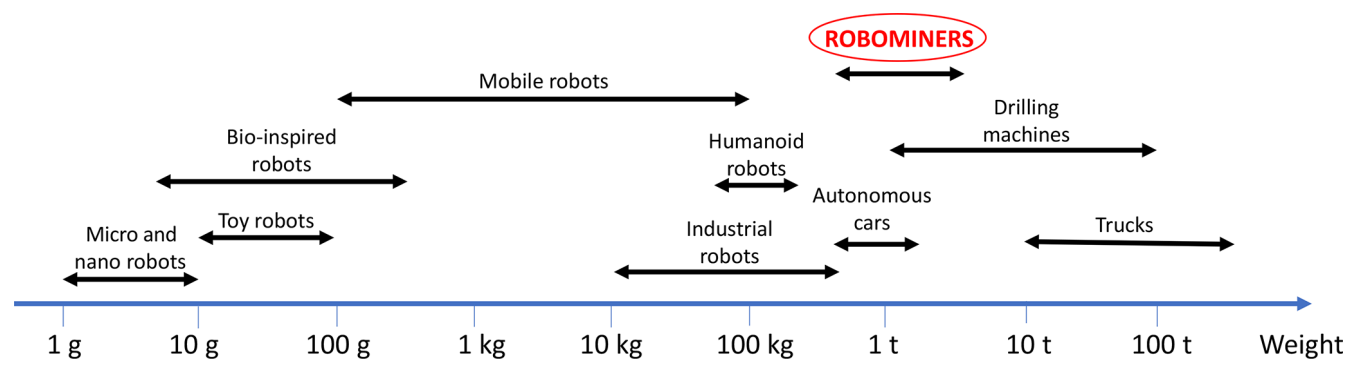

Figure 2. Weight comparison of different robotic systems and mining equipment. The robot-miner lies in the $1 \mathrm{t}$ range, heavier than most usual robots, but lighter than the conventional mining equipment currently used.

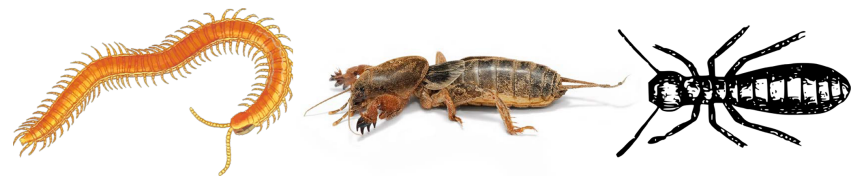

Figure 3. Animals as bio-inspiration for the robot-miner concept (centipede, mole cricket and termite).

the absence of a globally fixed coordinate frame. For localization, design considers both on proprioceptive sensing (inertial measurements) and exteroceptive sensors (tactile, temperature, pressure and other parameters that can be measured).

\subsubsection{Behaviour, navigation and control}

Navigation and robot control underground will follow the best practices seen in robotics nowadays. One example includes the use of simple but behavioural approaches that can be coupled with previous maps of the mines (when possible), which can decrease uncertainty in decision making processes. The control system will work hierarchically: the behaviour works at body level - it is in charge of generating control directives to the limbs. Then, limb control will generate trajectories for each of the components/segments of the limb. Finally, low level controllers generate suitable reference points (position, speed, force) for the individual actuators. During the initial stages of the project, the robot-miner will work with a data tether that allows monitoring, in real time, of the robot's current and planned activities.

\subsubsection{Heavy-duty actuation methods}

The aim is to employ hydrostatic drivetrains, using either a water or oil-based pressure medium. This is a technically feasible solution and offers numerous benefits in terms of improved power density and reduced system volume: reduces actuator diameters by $50 \%-70 \%$ and system flow-rate demand by a same factor. Reduced system flow rate then leads to a smaller and lighter pump, reduced pipe diameters and reduced tank volume. Furthermore, the use of a high system pressure offers benefits also in terms of generating ultra- high-pressure water to be used for hydrodemolition in support of ore extraction.

\subsubsection{Modularity}

Modularity is a crucial feature of the future miner. The idea is to make it possible to deliver the robot in pieces to the working area through small openings. Together with reconfigurability, which allow fault tolerance and flexibility to adapt the robot's size, power output and reach to a wide range of geological scenarios using standardised components, the modular robot-miner will show a big advantage compared to other mining methods (either conventional or innovative).

\subsubsection{Autonomy and resilience}

The robot's resilience will be shown in four areas, (1) redundancy, (2) physical reconfiguration, (3) adaptative behaviour and (4) reconfiguration. Resilience's core is based on the feedback loop: applying the Model-Driven Engineering and Model-Based Cognitive Control (Hernandez et al., 2015). The idea is the integration of a meta-controller in the control architecture, capable of perceiving the dysfunctional components of the system and reconfiguring it, just as feedback loops are used in classical control engineering processes to fill the gap between development and runtime phases. Autonomy for the modular system will also be studied, but the aim is to have the system work with a degree of autonomy that allows it to perform its tasks without human control.

\subsubsection{Selective mining ability}

Another important feature will be the robot's ability for selective real-time mining. The aim will be to (1) Adapt existing methods and sensors strategies and (2) develop new ones that will allow the robot to differentiate between ore and the waste rock. The perception sensors of the robot will allow the robot-miner to do selective mining by: (1) sensing and following main mineralization directions; (2) Apply the concept of "digestive mineralogy", by continuously sampling the drilling slurry produced; and (3) In-operation selection of best production tools. As a baseline for its sensing strategy, ROBOMINERS will follow a two levels implementation (1) 
very simple but reliable "default on-board sensors" that can readily provide basic information in real time and (2) develop a separate optional unit as a modular body segment that can contain sophisticated geochemical/mineralogical sensors capable of characterising slurry in real-time. Since the robot is modular, it will always be possible to add an "advanced mineralogical body segment" that is customised for any given deposit to be used for detailed on-board mineralogical analysis if this is required by the geo-environmental conditions:

1. Standard sensors will utilise the most basic physical properties (such as rock hardness), conductivity/resistivity, electrochemistry (electrochemical potential difference between the ore and the rock) and differences in thermal conductivity to maintain selective production of the ore. A continuous wave electromagnetic sensor can measure the current density anomalies produced by conductive bodies. A dynamic electrical resistivity system is able to map resistivity. Thanks to these the robot will always have 3D situational awareness in terms of its position in relation to the orebody and the waste rock and will be able to extract the ores even under fairly complex conditions.

2. The advanced unit will be an optional central segment (module) that can contain additional sensors that could be integrated in this segment of the robot. This segment will perform in-stream analysis of the drilling slurry using sampling inlet-outlet ports. A series of sensors will then characterise the slurry as it transits between the inlet and outlet ports. Considered techniques include:

a. LIBS (Laser-induced breakdown spectroscopy), as it covers a wide range of chemical elements, low detection limits, and is very sensible to light elements like lithium.

b. EDXRF (Energy dispersive X-Ray fluorescence), as it will allow a bulk analysis of the slurry

c. LINF (Laser-induced native fluorescence), as it is a very fast yet very sensible technique to identify rare earth minerals.

d. Deep Ultraviolet-Raman, as it is capable of characterising complex mineralogical assemblages, while reducing fluorescence interference to a minimum.

These sensors have recently been demonstrated in mining applications to characterise ore grades in drilling slurries (Cheng et al., 2017), tailings slurries (Khajehzadeh et al., 2017) and drill core mapping (Kuhn et al., 2017). Combined with more standard geophysical instruments (reflectance spectroscopy, conductivity, magnetic sensors) they can supply information on most ore types. Depending on the speed of mineralogical data processing we expect that realtime sensor data interpretation is possible and will provide continuous feedback to the robot as it wins the ore.

\section{Performance}

The robot-miner is currently under design and development, while the best tools and methods are already being tested and some also selected to be employed in the future prototype. Laboratory testing is to be followed by real-life testing in each of the three targeted areas (described in the Sect. 4.2) that represent three application mining scenarios where the technology can be applied (main targets, but not limited to these).

\subsection{Mining scenarios}

ROBOMINERS technology can be useful to mine deposits relevant in all main types of ore deposits, including magmatic, hydrothermal and sedimentary deposits (Hartai et al., 2020). Best targets include pegmatites, hydrothermal veins, carbonatites, orogenic gold or volcanogenic massive sulphides. The minerals of interest to be extracted include precious metals such as gold, silver and platinum, base metals like copper, iron and nickel, and others, including rare earth elements, lithium, graphite and more. The common factor is that the minerals are of intrinsically high value. Bulk construction, industrial minerals and chemical and energy minerals production is not envisaged as an appropriate target.

\subsection{Application scenarios}

\subsubsection{Abandoned and operating mines or sections with known remaining resources}

ROBOMINERS presents a solution for reopening many of Europe's abandoned underground mines. The closure of these mines was commonly related to economic and technological challenges (e.g. decreasing raw material prices, dewatering costs) rather than to depletion of mineral resources. Example: just in Europe, there are around 30000 closed mines (Didier et al., 2008), many with mineral potential. Mines in the Cornwall/Devon region, United Kingdom, fit under this criterion. With ROBOMINERS perhaps it will be possible to continue extraction in some of these sites, without large preparatory works.

\subsubsection{Small but high-grade mineral deposits and unexplored or explored non-economic occurrences}

With ROBOMINERS very small-scale deposits can be mined economically. In Europe there are thousands of small mineral deposits which have high concentration of metals but are too small to be extracted by conventional methods (i.e. unprofitable). Spatial distribution is also important: vein mineralisation which very commonly carry high concentrations of metals that are now considered as critical and are in high demand, are likely targets. Examples: Rare Earth Elements are classified as critical but are not yet mined in Europe, de- 
spite sites with potential being identified (Goodenough et al., 2016) (e.g. Finland, Sweden). Other examples include gold and silver (Las Cruces, Spain, Lagoa Salgada, Portugal, Tarina and Rodu, Romania; De Vos et al., 2005, Hewson et al., 2005), nickel and zirconium (Maniitsoq and Kringlerne, Greenland; Wittmer and Sievers, 2015). These are either small or low-grade deposits (or both), not economic with today's technologies, but that can be mined with ROBOMINERS approach. Suitable and helpful databases for potential European sites are Minerals4EU (http://minerals4eu. brgm-rec.fr/minerals4EU/, last access: 31 August 2020) and ProMine (http://www.europe-geology.eu/promine/, last access: 31 August 2020).

\subsubsection{Ultra depth, not accessible and hazardous environments}

Physical, technological and economical bottlenecks limit access to mineral deposits at greater depths, due to dewatering costs, heat, mechanical rock strength and stability, and other factors which drastically increase costs and risks of mining operations with conventional techniques. With ROBOMINERS, a borehole will be drilled from the surface to the deposit at depth. Surface and shallow-depth observations, as well as geophysical and geochemical data can be used as guides for mining areas of interest: data from $3 \mathrm{D}$ and $4 \mathrm{D}$ geological modelling shows some metallogenic belts with mineralisations of many types continuing to greater depths. Example: A mineral deposit with great lateral extent, in which ROBOMINERS could be applied at several locations, is the "Kupferschiefer" formation (Vaughan et al., 1989). It is a stratiform ore of copper, silver, lead and zinc which also contains enrichments of a series of other metals (e.g. gold, platinum, palladium). The thickness varies between $0.3-4 \mathrm{~m}$ only, but it represents a continuous stream from Poland to England. Kupferschiefer ores are currently mined in Poland from several large modern underground mines with active near-mine exploration and possible downdip extensions at a planning stage (Borg et al., 2012).

\subsubsection{ROBOMINERS economic feasibility}

A preliminary economic assessment for ROBOMINERS is done by using two scenarios: Scenario 1 - mining of copper ore from deep Kupferschiefer deposit, and Scenario 2 mining of a VMS (Volcanogenic Massive Sulfide) deposit. The most abundant seams of the Scenario 1 ore type are subhorizontal, $20-50 \mathrm{~cm}$ thick mineralisation zones, with copper content between $5 \%-15 \%$. Depth of the ore zone is between $600-1000 \mathrm{~m}$. The rock itself is a clay schist, embedded between sandstone and dolomite. While the conventional mining technique is not suitable for mining such thin ore seams, smaller ROBOMINERS could be potentially applied to extract such ore. The second scenario is extraction of ore from a volcanic massive sulphide deposit, rich in lead and zinc sul-
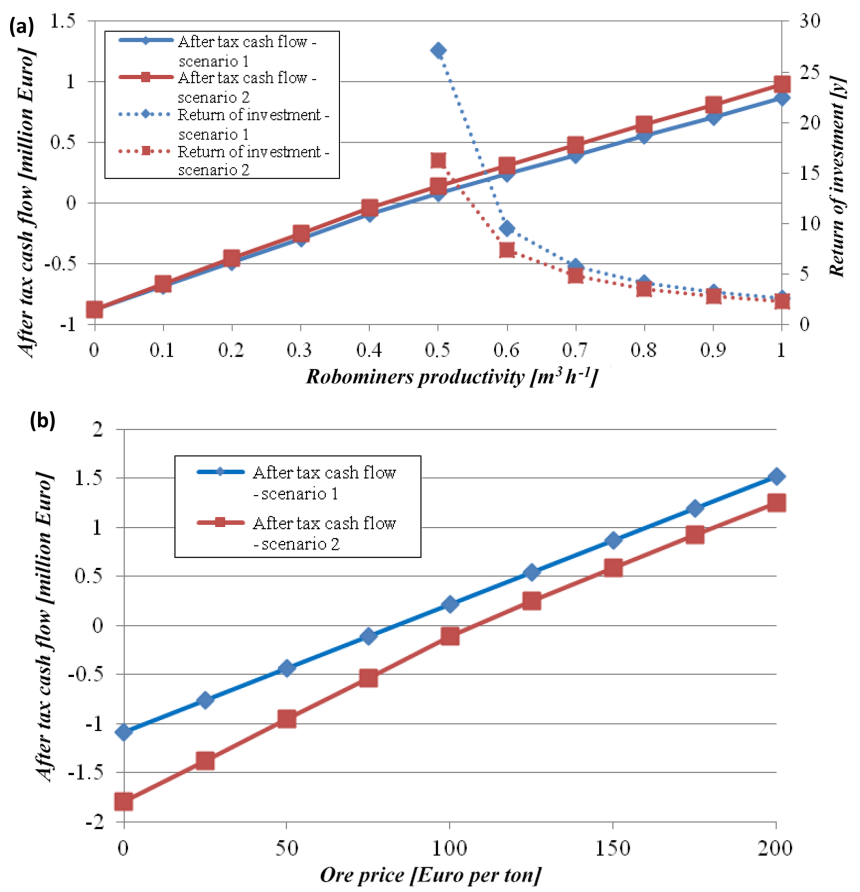

Figure 4. (a) Marginal profitability parameters for ROBOMINERS: scaling of expected productivity and after tax cash flow and return of investment. (b) Marginal profitability parameters: scaling of expected ore price and after-tax cash flow.

phides, where their content can reach 10\%-20\%. However, mineralisation is hosted in highly abrasive rocks. Such deposits, located in greater depths or smaller in their size, could be targeted (their size, depth or other specific factors prevents economic exploitation by using conventional mining).

The Robot-miner hydraulic unit cost was estimated to EUR 100 000, with 8 units simultaneously performing mining with capacity of $1 \mathrm{~m}^{3} / \mathrm{h}$ each with $35 \mathrm{~kW}$ of power and with operational time at $60 \%$, and ore price at 150 EUR per $\mathrm{t}$ for $7 \%$ copper ore (Scenario 1) and 180 EUR per t for $10 \%$ $20 \%$ lead-zinc ore (Scenario 2). The economic analysis includes investment costs, operational costs (tool consumption, energy and personnel costs, maintenance, depreciation costs and other miscellaneous costs), revenues from the sales of ore and revealed that potential return of investment could be less than 3 years for both scenarios (Table 1).

Figure 4 also shows that marginal ROBOMIENRS productivity for both scenarios is around $0.5 \mathrm{~m}^{3} / \mathrm{h}$ (with $60 \%$ operational time; Fig. 4a), and marginal ore price is around 100 EUR per $\mathrm{t}$ (if ROBOMINERS capacity is $1 \mathrm{~m}^{3} / \mathrm{h}$ at $35 \mathrm{~kW}$; Fig. 4b).

\subsection{Technology needs}

Different application environments will require different approaches from the robot-miner. This is one of the main reasons for its design to be modular. The possibility to per- 
Table 1. A preliminary cost/revenues model f-or ROBOMINERS application using two scenarios: Scenario 1 - mining of copper ore from deep Kupfersciefer deposit, and Scenario 2 - mining of VMS deposit. Robot-miner parameters are assumed to be: power $35 \mathrm{~kW}$, excavation capacity $1 \mathrm{~m}^{3} / \mathrm{h}$ and operational time $\left.60 \%\right)$.

\begin{tabular}{|c|c|c|c|}
\hline INITIAL INVESTMENT & & Scenario 1 & Scenario 2 \\
\hline Drilling cost & -1000000 & & \\
\hline Robot-miner machine cost & -800000 & & \\
\hline Infrastructure & -300000 & & \\
\hline Permits. documentation & -200000 & & \\
\hline TOTAL (EUR) & -2300000 & & \\
\hline \multicolumn{4}{|l|}{ OPERATIONAL COSTS (EUR per year) } \\
\hline Tool consumption cost & & 479347 & 919800 \\
\hline Energy cost & & 66536 & 66536 \\
\hline Personnel cost & & 500000 & 500000 \\
\hline Maintenance cost & & 50000 & 50000 \\
\hline Miscellaneous cost & & 100000 & 100000 \\
\hline Depreciation cost & & 160000 & 160000 \\
\hline \multicolumn{4}{|l|}{ REVENUES (EUR per year) } \\
\hline Sales of ore & & 2444040 & 3027456 \\
\hline \multicolumn{4}{|l|}{ TAX } \\
\hline Tax base & & 1088157 & 1231120 \\
\hline $20 \%$ Corporate income tax & & 217631 & 246224 \\
\hline After tax cash flow (1 year) & & 870526 & 984896 \\
\hline RETURN OF INVESTMENT (year) & & 2.64 & 2.34 \\
\hline
\end{tabular}

form different tasks will grant the miner's adaptability to several conditions. Some of the identified technology needs for mining different mineral deposit types include (Hartai et al., 2020):

- Ability to move in different directions coupled with directional drilling ( $\mathrm{cm}$ to $\mathrm{m}$ ahead),

- Set of mining production units (cutting/explosive/cavitation/LIBS/water-jet/percussion drilling/...) to use,

- Real-time chemical and mineralogical analysis,

- First-stage mineral processing to separate a concentrate feed from waste rock,

- Slurry pumping system to bring mineral concentrates to surface or to an underground pre-concentrator robot, and waste rock slurry to a backfill in the mined area,

- Rock-bolting or other tunnel stabilisation system to maintain structural integrity of the mine,

- Sensor support such as video camera(s) for hazard detection and battery recharge system.

\subsection{Future vision}

During the project lifetime - up to May 2024 - the research and development will be based on the robot-miner itself and the mining system, driven by future visions and goals for 2030 and 2050. Efforts correspond to incrementing steps in the transfer from design to laboratory to field testing to commercial application (with corresponding higher TRL levels). Figure 5 summarises the work to be carried out during the project, as well as it highlights the expected evolution of this technology by 2030 and 2050, in different relevant areas.

ROBOMINERS development is also driven by current and future trends in mining and robotics related fields and assessed through a continuous foresight process, which includes experts' consultation, horizon scanning and roadmapping. Together, these will guarantee that development and ultimately, the vision, of the robot-miner and supporting technology can be tailored to real-life changing conditions.

\section{Conclusions}

ROBOMINERS is developing proof of concept technology to exploit small and difficult to access mineral deposits, in a niche where conventional mining cannot operate economically. The vision of ROBOMINERS entails a new mining perspective based on state-of-the-art robotics and min- 


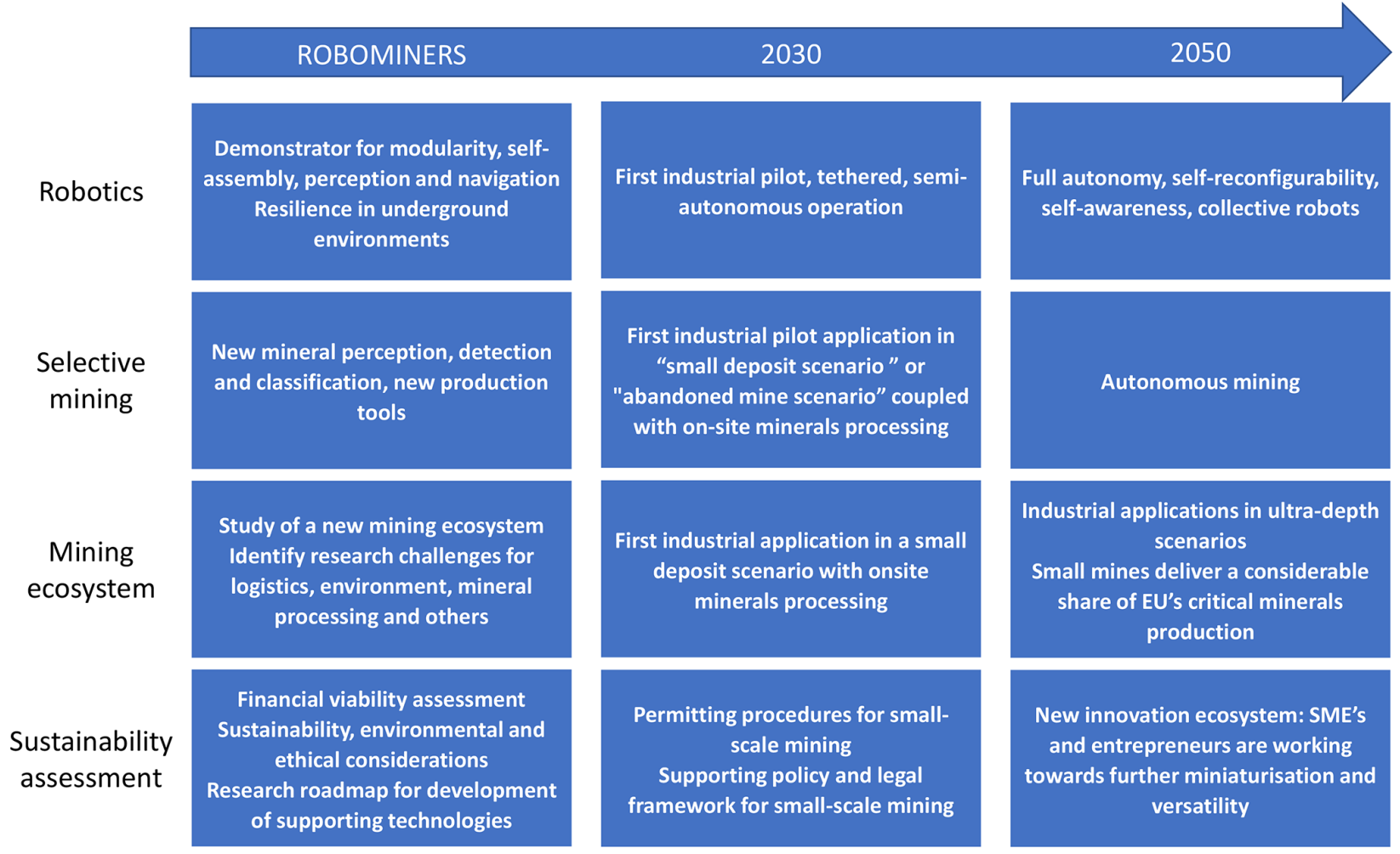

Figure 5. ROBOMINERS visions for the future on four different areas of relevance.

ing related technologies, that, when linked, will make mining of specific deposits economically valuable while supporting better environmental practices and social acceptance for the mining industry. Work is ongoing with the definition and design of the systems and is driven by 2030 and 2050 targets set by ROBOMINERS project. The ROBOMINERS technology will not be a robotic extraction machine alone; instead, the whole production cycle should undergo serious modifications, creating not only an upgraded variety of old established technologies, but a revolutionary new approach. It may be a powerful tool for the resource management industries of tomorrow or even in the more distant future in a narrow segment of mineral raw materials.

Data availability. The research is based on ROBOMINERS project (https://cordis.europa.eu/project/id/820971, last access: 15 October 2020), which started in June 2019. To develop the paper we based ourselves on the Grant Agreement signed between the consortium and the European Commission; the document contains pertaining information for the project's background, impact and description of work which are to a lesser extent replicated in this article. This document is not available to be consulted outside the Consortium-European Commission scope.

Author contributions. All authors contributed to the development and internal review of this article.
Competing interests. The authors declare that they have no conflict of interest.

Disclaimer. This document reflects only the authors' view and the European Commission is not responsible for any use that may be made of the information it contains.

Special issue statement. This article is part of the special issue "European Geosciences Union General Assembly 2020, EGU Division Energy, Resources \& Environment (ERE)". It is a result of the EGU General Assembly 2020, 4-8 May 2020.

Acknowledgements. Special thanks to all the ROBOMINERS project consortium participants that helped and are helping in the development of the project.

Financial support. This research has been supported by the European Commission Horizon 2020 research and innovation programme (ROBOMINERS, grant no. 820971).

Review statement. This paper was edited by Sonja Martens and reviewed by Juan Alcalde, Christopher M. Keane, and one anonymous referee. 


\section{References}

Borg, G., Piestrzyński, A., and Bachmann, G.: An Overview of the European Kupferschiefer Deposits. Society of Economic Geologists, Inc. Special Publication 16, 455-486, 2012.

Cheng, X., Yang, X., Zhu, Z., Guo, L., Li, X., Lu, Y., and Zeng, X.: On-stream analysis of iron ore slurry using laser-induced breakdown spectroscopy, Appl. Optics, 56, 9144-9149, 2017.

De Vos, W., Batista, M., Demitriades, A., Duris, M., Lexa, J., Lis, J., and O'Connor, P. J.: Metallogenic mineral provinces and world class ore deposits in Europe, in: FOREGS Geochemical Atlas of Europe, part 1, Background Information, Methodology and Maps, edited by: Salminen, R., Geological Survey of Finland, Finland, 43-49, 2005.

Didier, C., Van der Merwe, J. N., Bétournay, M., Mainz, M., Kotyrba, A., Aydan, Ö., and Song, W. K.: Mine Closure and PostMining Management, International State-of-the-art report, International Commission on Mine Closure, International Society for Rock Mechanics, https://doi.org/10.13140/2.1.3267.8407, 2008.

European Commission: $\operatorname{COM}(2008) 699$ final, Communication from the Commission to the European Parliament and the Council, The raw materials initiative - meeting our critical needs for growth and jobs in Europe, 14 pp., available at: https://eur-lex.europa.eu/legal-content/EN/TXT/HTML/ ?uri=CELEX:52008DC0699\&from=EN (last access: 14 October 2020), 2008.

European Commission: COM(2019) 640 final, Communication from the Commission to the European Parliament, the Council, the European Economic and Social Committee and the Committee of the Regions, The European Green Deal, 24 pp., available at: https://eur-lex.europa.eu/legal-content/EN/TXT/HTML/ ?uri=CELEX:52019DC0640\&from=EN (last access: 14 October 2020) 2019.

European Commission: $\operatorname{COM}(2020) 474$ final, Communication from the Commission to the European Parliament, the Council, the European Economic and Social Committee and the Committee of the Regions, Critical Raw Materials Resilience: Charting a Path towards greater Security and Sustainability, 24 pp., available at: https://eur-lex.europa.eu/legal-content/EN/TXT/HTML/ ?uri=CELEX:52020DC0474\&from=EN, last access: 14 October 2020.

Forge, S. and Blackman, C.: A Helping Hand for Europe: The Competitive Outlook for the EU Robotics Industry, JRC Scientific and Technical Reports, 119 pp., 2010.

Goodenough, K., Schilling, J., Jonsson, E., Kalvig, P., Charles, N., Tuduri, J., and Keulen, N.: Europe's rare earth element resource potential: An overview of REE metallogenetic provinces and their geodynamic setting, Ore Geol. Rev., 72, 838-856, 2016.
Hartai, E., Németh, N., Földessy, J., Henley, S., Žibret, G., and Galos, K.: Review document giving scope and examples of deposit types of interest, ROBOMINERS Deliverable 5.1, 77 pp., 2020.

Hernandez, C., Fernandez, J., Sanchez-Escribano, G., BermejoAlonso, Jm. and Sanz, R.: Model-Based Metacontrol for Selfadaptation, Proc. ICRA 2015, 643-654, 2015.

Hewson, N., Leary, S., and Feier, N.: Tarina and Rodu: Gold mineralisation hosted in maar-diatreme contact environments in 40 the Apuseni Mountains, Romania, Geochemistry, Mineralogy, Petrololgy, 43, 93-101, 2005.

Khajehzadeh, N., Haavisto, O., and Koresaar, L.: On-stream mineral identification of tailing slurries of an iron ore concentrator using data fusion of LIBS, reflectance spectroscopy and XRF measurement techniques, Miner. Eng., 113, 83-94, 2017.

Koivurova, T., Buanes, A., Riabova, L., Didyk, V., Ejdemo, T., Poelzer, G., and Lesser, P.: 'Social license to operate': a relevant term in Northern European mining?, Polar Geography, 38, 35 pp., 2015.

Kuhn, K., Meima, J., Rammlmair, D., and Ohlendorf, C.: Chemical mapping of mine waste drill cores with laser-induced breakdown spectroscopy (LIBS) and energy dispersive X-ray fluorescence (EDXRF) for mineral resource exploration, J. Geochem. Explor., 161, 72-84, 2017.

Lepora, N., Verschure, P., and Prescott, T.: The state of the art in biomimetics, Bioinspir. Biomim., 8, 013001, https://doi.org/10.1088/1748-3182/8/1/013001, 2013.

Russell, R: CRABOT: A biomimetic burrowing robot designed for underground chemical source location, Adv. Robotics, 25.1-2, 119-134, 2011.

Vaughan, D. J., Sweeney, M., Friedrich, G., Diedel, R., and Haranczyk, C.: The Kupferschiefer:An Overview with an Appraisal of the Different Types of Mineralization, Econ. Geol., 84, 10031027, 1989.

Wittmer, D. and Sievers, H.: European Raw Material Potential - Thematic Report I. Minerals4EU project deliverable, 53 pp., available at: http://minerals4eu.brgm-rec.fr/sites/ default/files/Minerals4EU_Foresight-Study_Topic-Report-I_ European-RM-Potential.pdf, (last access: 14 October 2020, 2015.

Zagal, J. C., Armstrong, C., and Guang Li, S.: Deformable Octahedron Burrowing Robot, In the International Conference on the Synthesis and Simulation of Living Systems, Artif. Life, 13, 431-438, 2012. 